\title{
Patrimonio colectivo. Comunidades, participación y sostenibilidad
}

\author{
Beatriz Santamarina Campos | Dpto. de Sociología y Antropología Social, \\ Universitat de València \\ URL de la contribución <www.iaph.es/revistaph/index.php/revistaph/article/view/5000>
}

\section{RESUMEN}

El patrimonio cultural se nos presenta como un campo de intervención y gobierno en constante mutación. Lejos de ser sustantivo, sea este calificado como material, natural e inmaterial, es una realidad sociohistórica mediada por las condiciones sociales de producción. Desde una perspectiva crítica, en este artículo, hacemos una aproximación al patrimonio colectivo poniendo atención a las transformaciones experimentadas en las últimas décadas. La entrada de la democratización patrimonial y el giro participativo a raíz de la Convención para la Salvaguardia del Patrimonio Cultural Inmaterial (París, 2003) parece no haber tenido el calado esperado. El papel activo otorgado a las llamadas "comunidades portadoras" en las activaciones y gestión patrimonial se ha reducido a lo retórico, produciéndose una contradicción entre las proclamas y las prácticas lanzados por los discursos patrimoniales autorizados. Y esto no es extraño, en juego está la posesión, propiedad y titularidad, de los bienes. De ahí, que los conflictos por la disputa de lo patrimonial sean cada vez más numerosos, imponiéndose regímenes patrimoniales que responden a las lógicas imperantes del mercado. Hoy, más que nunca, la degradación ecosistémica nos obliga a replantear el patrimonio colectivo como una herramienta para lograr la sostenibilidad, siguiendo los Objetivos de Desarrollo Sostenible formulados globalmente para la Agenda 2030. Desde nuestra perspectiva, el reto para alcanzar un patrimonio colectivo democrático, colaborativo y sostenible pasa por un cambio radical en los regímenes patrimoniales actuales.

\section{Palabras clave}

Comunidad | Dominación | Empoderamiento | Gobernanza | Objetivos de desarrollo sostenible | Participación ciudadana | Patrimonio colectivo | Poder | Sostenibilidad | 


\section{INTRODUCCIÓN: EL PATRIMONIO COLECTIVO}

1

Siguiendo a Geismar (2015), el concepto de régimen patrimonial es útil porque permite aproximarse al patrimonio colectivo desde la política y la gobernanza.
El patrimonio cultural es un concepto confuso y, a su vez, brillante. Si bien parece fácil la identificación semántica del término patrimonio, su calificativo cultural conlleva parejas enormes dificultades. En realidad, toda fragmentación del patrimonio es cultural, porque cualquier disección que se practique siempre obedece a una determinada praxis cultural. Sin embargo, la separación del patrimonio cultural en material, natural e inmaterial, como objetos y sujetos de fiscalización, tiene una larga tradición en el mundo occidental. Desde el siglo XIX se consolidó esta triple desmembración del patrimonio colectivo apareciendo el llamado patrimonio cultural (material), encapsulado en los monumentos; el patrimonio natural, circunscrito a los parques naturales; y el (incómodo) folklore, bien representado en los parques costumbristas escandinavos. El patrimonio decimonónico sentó las bases de una separación forzada y casi imposible, amparada en el conocimiento científico y muy eficaz en términos políticos. Quizás, lo más destacable del proceso es que asimiló y presentó el patrimonio colectivo en términos de patrimonio cultural, reservando esta denominación para la definición humanista de cultura (Pavone 2008; Santamarina Campos y Mármol 2019). Los usos del pasado se tornaron en herramientas, de una enorme eficacia simbólica, para el Estado nación (Anderson 1983). El nacionalismo bebió del romanticismo, se aprovechó de la compartimentación científica y supo sacar partido a los distintos patrimonios para legitimar sus proyectos políticos: el genio creativo, la naturaleza patria o el espíritu del pueblo fueron fuentes inagotables para consolidar el esqueleto de proyectos identitarios a través de símbolos elevados a marcadores nacionales (Daniels 1993; Choay 1996; Prats 1997; González-Varas 1999; Poulot 2006; Casado de Otaola 2010). De hecho, fueron utilizados, según conveniencia, para asentar las bases de los primeros regímenes patrimoniales ${ }^{1}$, articulados a través de un pasado y tradición naturalizados (Lowenthal 1998; Hobsbawm y Ranger 2005).

No vamos a entrar en ello. Pero sí, de una forma breve y sintética, hemos querido arrancar mirando a la primera configuración de lo que llamaremos, a partir de ahora, patrimonio colectivo; porque en ella encontramos las claves para poder acercarnos a comprender el papel o el peso otorgado a las comunidades, así como las implicaciones del patrimonio en el alcance de los objetivos de desarrollo sostenible (ONU 2015). Desde nuestro punto de vista, el enredo conceptual forma parte del éxito de su formulación. Nadie podrá negar que la expresión "patrimonio cultural" es un enunciado tan enrevesado, vago y permeable, como sobreentendido. Los potentes imaginarios de poder, encapsulados en lo patrimonial, permiten definir su realidad escudados en criterios de verdad de carácter axiomático (Foucault 1980) y ratificados en la autenticidad (Frigolé 2014; Mármol y Estrada 2018). El patrimonio colectivo, como realidad dada, se desliga de sus condiciones sociales de producción (Mármol 2017). Su plasticidad espacio-temporal y 
su capacidad de adaptación muestran cómo, en realidad, el mismo carecería de todo sentido sin agencias y agentes patrimonializadores (Hernández i Martí et ál. 2005; Montenegro Riveros 2010). Pese a los cambios experimentados (Ariño Villarroya 2002; González-Varas 2015), el trasfondo no ha cambiado en substancia (Santamarina Campos 2013). La llamada "democratización patrimonial" y la manida participación pueden tener efectos perversos (Noyes 2011) o ser simplemente "patrimonio participativo 2.0 a coste cero" (Quintero Morón y Sánchez-Carretero 2017, 61).

Ahora bien, las mutaciones sufridas responden a exigencias del contexto socioeconómico y a las demandas de colectivos marginados de los regímenes patrimoniales (no marginales). Con respecto a lo primero, el patrimonio colectivo es una realidad sociohistórica, mediada por las relaciones y medios sociales de producción, donde se seleccionan ciertos acervos culturales, elevándolos a la categoría de patrimonio colectivo. Por tanto, lejos de las visiones sustantivistas del patrimonio (Davallon 2014), lo consideramos un proceso en constante transformación y una forma más de gobierno (Bendix, Eggert y Peselmann 2013; Cesari 2013; Coombe y Weiss 2015; Alonso González 2017). Y en relación a lo segundo, las peticiones de comunidades o colectivos han venido sucediéndose, sobre todo, desde el último tercio del siglo pasado ${ }^{2}$, quedándose la mayoría de ellas en respuestas circunscritas al ámbito de lo políticamente correcto (Gómez Ferri 2004; Albert Rodrigo 2005; Quintero Morón y Sánchez-Carretero 2021). Por poner un ejemplo, en la esfera internacional, donde dicta los preceptos globalizados la Organización de las Naciones Unidas para la Educación, la Ciencia y la Cultura (Unesco), el calado esperado, sobre todo tras la Convención para la Salvaguardia del Patrimonio Cultural Inmaterial (París, 2003), ha quedado, aparentemente, en papel mojado ${ }^{3}$.

Sin duda, lo apuntado complica sobre manera una aproximación rápida al patrimonio colectivo, aunque ayuda a situarlo como un campo ideológico y político (Kuutma 2013; Tauschek 2013; Geismar 2015). Las versiones autorizadas del patrimonio colectivo o el llamado discurso patrimonial autorizado (AHD) ${ }^{4}$ no solo responden a las cosmovisiones occidentales, sino que también contribuyen a legitimar y consolidar las hegemonías (Smith 2006; Labadi 2007; Winter 2014) ${ }^{5}$. Las activaciones patrimoniales suponen un proceso de discriminación y control de valores a través de la jerarquización de distintos géneros culturales. Y la asignación de sentidos siempre responde a regímenes políticos (patrimoniales) (Bendix, Eggert y Peselmann 2013; Geismar 2015). En el patrimonio está en juego el capital simbólico, en términos bourdianos, tras la distinción, la diferencia y la exclusividad está la disputa real de la producción, distribución y circulación de bienes (materiales, inmateriales y naturales). Más allá de cuestionar el qué, para qué, a quién o para quién, bajo tecnologías de representaciones, el patrimonio colectivo faculta para observar la pugna y apropiación del capital social, cul-
2

En realidad, desde 1960, ya podemos empezar a rastrear la petición de la democratización de distintos ámbitos o la presión para que se reconozcan los derechos de autor y el conocimiento local (vinculado a la biodiversidad) y las políticas culturales (Kurin 2004).

3

Volveremos al papel hegemónico ocupado por la Unesco y la Convención del 2003 más adelante.

4

Utilizamos sus siglas en inglés (Authorized Heritage Discourse). Acuñado por Smith, el AHD "is the dominant Western discourse about heritage that works to naturalize a range of assumptions about the nature and meaning of heritage" (Smith 2006, 4).

5

De ahí que hayamos empezado diciendo que el concepto "patrimonio cultural" es brillante, porque la categoría goza de gran aceptación social a la vez que esconde su naturaleza política. 
tural y económico (Bourdieu 1991, 1997, 1998; García Canclini 1999), como un campo conflictivo (Tunbridge y Ashworth 1996; Sánchez-Carretero 2017; Santamarina y Mármol 2020). La perspectiva crítica del patrimonio permite atender a los procesos desigualitarios en su producción, a los desplazamientos generados por la sustracción o silenciamiento de comunidades y grupos, a las resistencias forjadas por las distintas racionalidades impuestas y a las relaciones de dominación establecidas a partir de las lógicas de clasificación y dependencia (Bendix 2009; Heinich 2010; Bortolotto 2011; Mármol, Morell y Chalcraft 2015; González-Varas 2015; Mármol, Siniscalchi y Estrada 2016; Sánchez-Carretero 2017; Santamarina y Mompó 2021).

En este artículo, prestaremos especial atención, en primer lugar, a cómo las transformaciones de los procesos patrimoniales han puesto su punto de mira en las comunidades, estableciendo un triple desafío: la democratización, la participación y la sostenibilidad. En segundo lugar, atenderemos al patrimonio colectivo como un instrumento potencial para alcanzar los objetivos del desarrollo sostenible, a través de una apuesta política y real transformadora. $\mathrm{Y}$, por último, cerraremos con unas breves conclusiones, donde el reto para alcanzar un patrimonio colectivo democrático, colaborativo y sostenible pasa por un cambio radical en los regímenes patrimoniales actuales.

\section{DE LA COMUNIDAD IMAGINADA A LA COMUNIDAD PORTADORA, DEL TENER AL SER PATRIMONIAL}

6

Todavía minoritario (Quintero-Morón 2020; Bingham et ál. 2021)

7

Su papel ideológico es indiscutible en la conservación, salvaguardia y gestión patrimonial. Este ha ido creciendo a través de sus convenciones y recomendaciones, generando una creciente burocratización. Sus criterios y preceptos, secundados por la mayoría de países, son visibles en las políticas nacionales y locales, como veremos en el apartado siguiente (Ashworth y Van der Aa 2006; Askew 2010; Nielsen 2011; Villaseñor y Zolla 2012).
Hoy, la maquinaria patrimonial ha traído consigo nuevas propuestas de gestión y de gobernanza, en principio, con el objetivo de democratizar el ámbito patrimonial. Pero, lejos de alcanzar el propósito, se reproducen las fórmulas de normalización e institucionalización patrimonial, entrando en un mentís los discursos y las prácticas. Esto genera múltiples paradojas al reproducir las desigualdades estructurales que son, precisamente, las que se quieren evitar. A pesar del trabajo de participación implementado en algunas administraciones o desplegado desde ámbitos científicos ${ }^{6}$, éste acaba en pura retórica con la imposición de objetos y sujetos, sean estos sitios, lugares, memorias, o conocimientos. El patrimonio neoliberal vigente, con la explosión patrimonial y la centralidad del mercado, entra en contradicción con los propios postulados lanzados desde la Unesco. Este organismo ha sido fundamental para la regulación y protección de los bienes patrimoniales, a la par que un instrumento para la homogenización e imposición de las formas patrimoniales (Herzfeld 2004) ${ }^{7}$. En cualquier caso, ha atendido a las demandas y ha contribuido a los cambios experimentados situando "la democratización de la gestión como un elemento fundamental de los actuales Estados" (Quintero-Morón y Sánchez-Carretero 2017, 57). Entre los giros patrimoniales más destacables está la voluntad de convertir a las comunidades en protagonistas de su patrimonio, a través del llamado giro participativo 


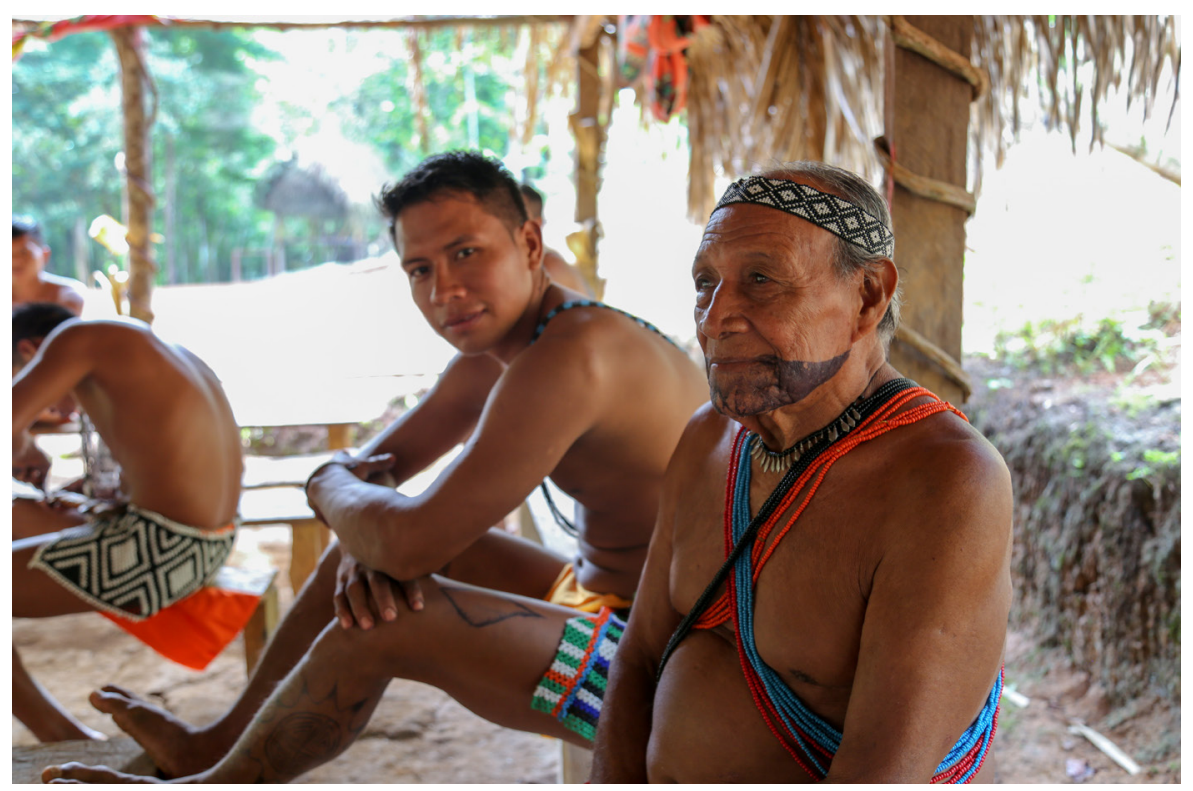

(Sánchez-Carretero et ál. 2019), coincidiendo con un movimiento de calado entre el tener y el ser patrimonial (Santamarina y Mármol 2020).

Para entender el papel conferido a las comunidades locales, hay que retrotraerse a la Convención para la Salvaguardia del Patrimonio Cultural Inmaterial. En ella la Unesco establecía un viraje importante. De una parte, reconocía, por primera vez, al patrimonio inmaterial como categoría a salvaguardar; de otra, dotaba a las comunidades de un peso notable. Nos centraremos en lo segundo, las comunidades, sin entrar en una discusión teórica sobre este polisémico, frágil, imaginado, fragmentado y reificado concepto (Hall 2003, 2010; Bauman 2001, 2004, 2005). No obstante, esa comunidad imaginada vinculada al Estado nación referida por Anderson (1983) es sustituida aquí por unas pretendidas comunidades ${ }^{8}$ portadoras de lo patrimonial: locales, diversas, reales, concretas y situadas espacio-temporalmente, uniformes y bienintencionadas, con capacidad de aglutinar un todo armónico (sin fisuras) y patrimonial (Waterton y Smith 2010; Quintero Morón y Sánchez-Carretero 2017; Quintero-Morón 2020) ${ }^{9}$. Al margen de reproducir los cánones decimonónicos, en una escala menor o microescala, esa vuelta a la esencialización e idealización remite, en muchos casos, a la fantasía del buen salvaje.

El propio documento contenía hasta diez veces la palabra "comunidades". Ya en su preámbulo, recogía la necesidad de "un diálogo renovado entre las comunidades" y, explícitamente, se decía: "Reconociendo que las comunidades, en especial las indígenas, los grupos y en algunos casos los individuos desempeñan un importante papel en la producción, la salvaguardia, el man-
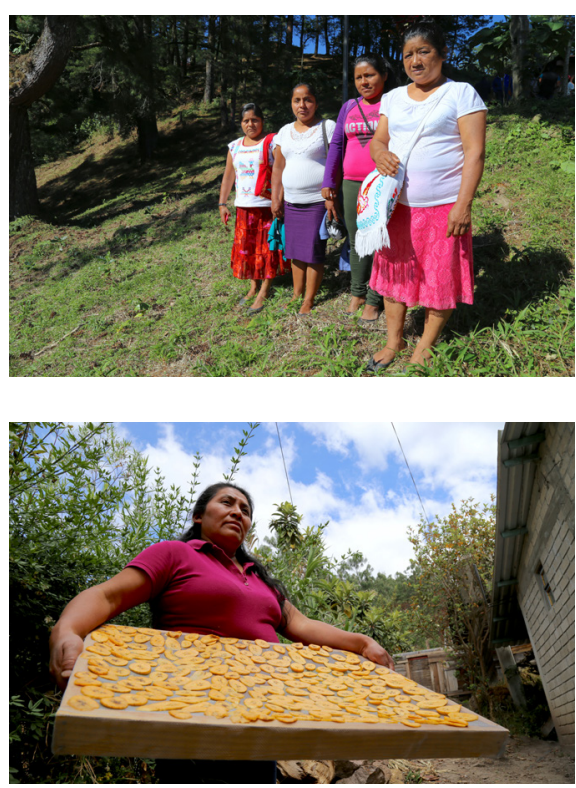

Las pretendidas comunidades portadoras de lo patrimonial implica una esencialización e idealización que remite, en muchos casos, a la

fantasía del buen salvaje. En las imágenes, pueblos Indígenas y comunidades locales en Panamá (izquierda) y Oaxaca, México, a la derecha | fotos Banco Mundial América Latina y el Caribe

8

El texto hace referencia a comunidades $y$ grupos (e incluso individuos, un guiño a otras prácticas), aquí usaremos comunidad local para referirnos a ambos.

Para una mayor profundización sobre la utilización del término comunidad en la Unesco de puede acudir a Hertz (2015) y Quintero Morón y Sánchez-Carretero (2017). 
10

No entraremos a analizar "en especial las indígenas", tan solo queremos señalar su significativa alusión. En gran medida su inclusión respondía a los movimientos dados, a finales del XX, después de las presiones y demandas de numerosos colectivos, como el Decenio de la ONU para las poblaciones Autóctonas y Minoritarias o el borrador de la Declaración de la ONU sobre derechos de los pueblos autóctonos (Aikawa 2004)

\section{1}

La creatividad traspasaba así los límites de exclusivo genio creativo.
La llamada "democratización patrimonial" y la manida participación pueden tener efectos perversos o ser simplemente "patrimonio participativo 2.0 a coste cero". En la foto, VII Expo Colchane que organizan las comunidades junto al municipio | foto Gobierno Regional de Tarapacá (Chile) tenimiento y la recreación del patrimonio cultural inmaterial, contribuyendo con ello a enriquecer la diversidad cultural y la creatividad humana"10. Por primera vez, este organismo internacional consagrado a velar por el patrimonio colectivo hablaba de la importancia de las comunidades, como agentes portadores, productores y dinámicos, vehiculándolas además con la diversidad y la creatividad ${ }^{11}$. De facto, el artículo 1 platicaba sobre las finalidades de la Convención y, en su punto 2 (b), establecía el "respeto del patrimonio cultural inmaterial de las comunidades".

El artículo 11 confería a los Estados parte la labor de "identificar y definir los distintos elementos del patrimonio cultural inmaterial presentes en su territorio, con participación de las comunidades, los grupos y las organizaciones no gubernamentales pertinentes". Dejando al margen la sorprendente equiparación, al menos en plano discursivo, entre las comunidades y las organizaciones no gubernamentales, se asignaba a los Estados la función de garantizar la participación de las comunidades en la difícil tarea de inventariar y catalogar el patrimonio inmaterial (Mármol, Roigé y Estrada 2011). El artículo 15 daba un paso más firme en este reconocimiento y, bajo el epígrafe "Participación de las comunidades, grupos e individuos", exhortaba a los Estados parte a "lograr una participación lo más amplia posible de las comunidades, los grupos y, si procede, los individuos que crean, mantienen y transmiten ese patrimonio y de asociarlos activamente a la gestión del mismo". Ya no se trataba tan solo de otorgarles un papel dinámico en las activaciones, había que incluirlas también en la gestión patrimonial, un campo reservado hasta el momento a técnicos, burócratas y expertos. Además, este reconocimiento a las comunidades locales, como portadoras

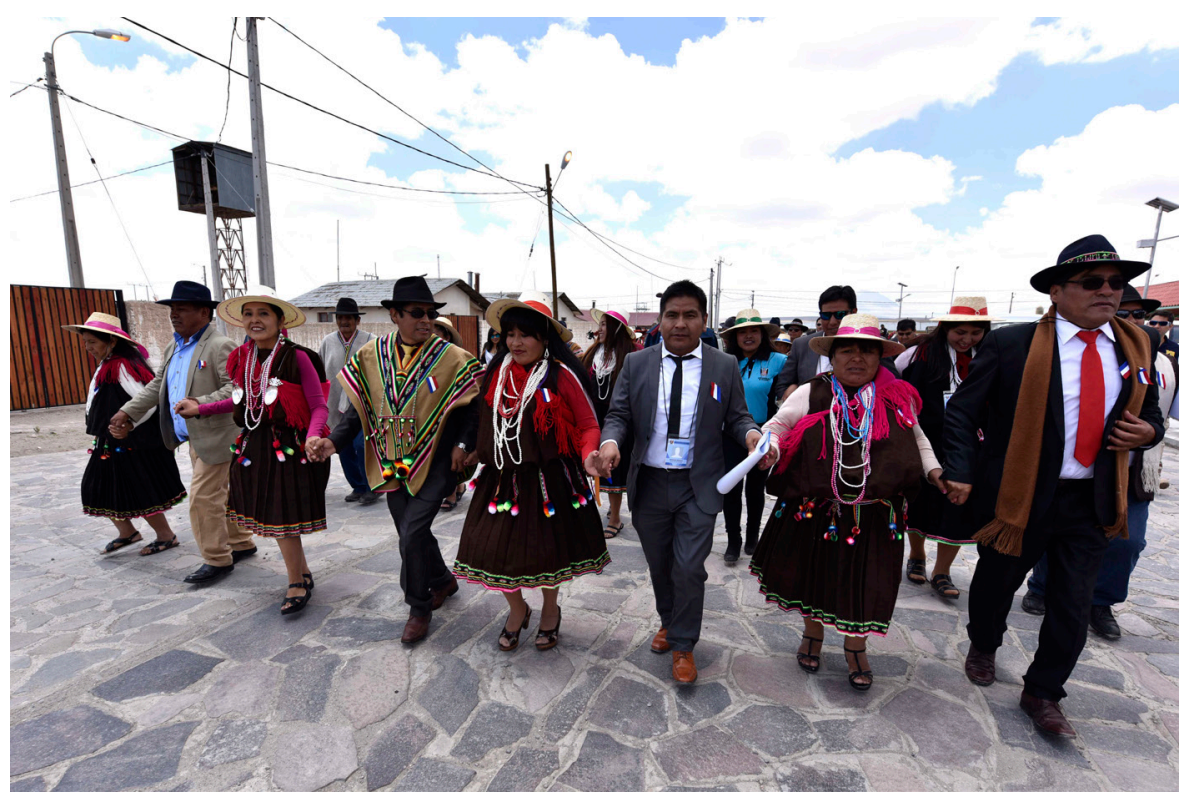


indiscutibles de su patrimonio, se traducía en la necesidad de incorporar en los expedientes el apoyo explícito de las mismas para elevar cualquier petición de inclusión en la Lista de Patrimonio Cultural Inmaterial.

Con todo no ha reportado cambios sustanciales. La pretendida "comunidad" portadora no deja de ser una amalgama discursiva que obvia los conflictos internos y las reivindicaciones dispares, del mismo modo que los manejos patrimoniales conllevan litigios y demandas. Sus engañosas naturalizaciones -tanto de la comunidad como del patrimonio presentados ambos como realidades sustantivas- no pueden encubrir las disputas por posesión de los bienes, sean materiales, inmateriales o naturales. Los conflictos patrimoniales son habituales porque chocan entre sí agentes y agencias con lógicas, intereses y prácticas heterogéneas y, en muchos casos, antagónicas. Si hablamos del papel de las "comunidades" en los procesos patrimoniales éste es doble: dinámico y crítico. Las comunidades tienen capacidad para proponer activaciones patrimoniales, como sujetos/objetos activos, bien por su propio interés o bien como coyuntura política. Los distintos patrimonios contenidos en una comunidad pueden ser reivindicados, reinventados o adjudicados por sus diferentes miembros. Además, algunos colectivos pueden poner en jaque las declaraciones patrimoniales, al discutir el trasfondo de la pretendida patrimonialización, sea esta local, estatal o internacional, y reclamar para sí lo patrimonializado poniendo en evidencia cómo dentro de las comunidades se pueden tener visiones encontradas sobre su patrimonio. Por poner un ejemplo, la comunidad fallera se presenta como portadora categórica de su patrimonio material e inmaterial y se da por hecho que el mundo fallero en su conjunto celebró la proclama de su fiesta como Patrimonio Cultural Inmaterial de la Humanidad ${ }^{12}$. No obstante, tras esa pretendida uniformidad, aparecieron movimientos en contra de la declaratoria como el colectivo Falles Populars i Combatives, quienes se posicionaron con una fuerte carga satírica, propia del universo fallero, frente al Patrimoney y a la Unasco, reclamando sus fiestas como propias y locales y alertando sobre el riesgo del mercadeo de la cultura (Santamarina y Mármol 2020). La que hemos denominado la "oportunidad política del patrimonio" puede ayudar a entender cómo el patrimonio colectivo puede transformarse en un potente activo político, con una gran capacidad de movilización. Dentro de una misma comunidad, en diferentes contextos y por distintos agentes, podemos observar su versatilidad, como instrumento legitimador, como arma reivindicativa o como herramienta alternativa para articular identidades y territorios (Santamarina y Mompó 2021).

Abrir a la participación, en sentido amplio, es poner sobre la mesa la legitimidad sobre pertenencia, dominio y apropiación de lo patrimonial. Y esto, evidentemente, es peliagudo y restringe el alcance de la propuesta normativa de la participación. No es extraño que el giro participativo se haya quedado en una aspiración de corte ético. Las preguntas "qué es" y "de quién es" lo
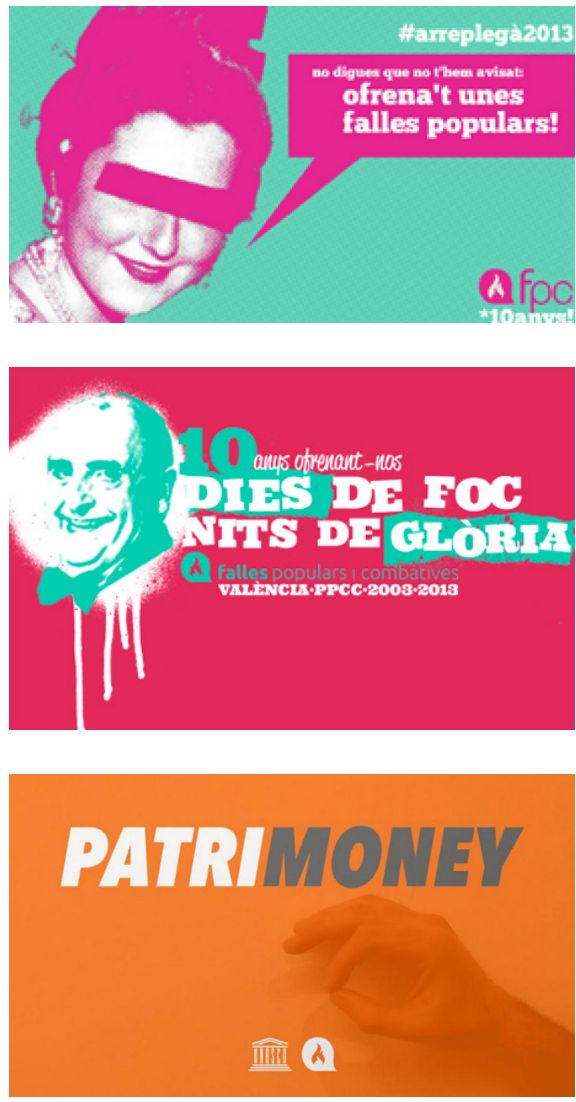

Diferentes carteles del colectivo Falles Populars y Combatives de Valencia

12

El Espacio Cultural de la fiesta de las Fallas fue incluido en 2016 en la Lista Representativa del Patrimonio Cultural Inmaterial de la Humanidad. 
La bibliografía, en este sentido, es amplísima. Para una revisión del caso español se puede acudir a Beltrán y Santamarina (2016).

14

En el informe no estaban todos los datos actualizados por lo que se daba por hecho que se había alcanzado, en 2021, con la protección de la superficie terrestre (17\%) y marina (10\%) pactada en el Convenio.

15

En este sentido "gentrification is seen as a manifestation of more generalised and indeed globalised processes of capitalist 'uneven development”' (Phillips et ál. 2008, 57).
El modelo patrimonial de la naturaleza se ha basado en una triple expropiación: del territorio, de las condiciones sociales de producción y de los conocimientos y memorias. En la imagen, cartel reivindicativo en Canadá en contra de la expansión de un parque nacional | foto Beatriz Santamarina Campos patrimonial ponen en tela de juicio la titularidad y propiedad de los bienes. Lejos de referirnos al patrimonio colectivo como algo simbólico, su activación tiene efectos reales y prácticos sobre las comunidades. El "para quién es" y "para qué es" acaban situando al artefacto patrimonial en las lógicas político-económicas imperantes. Numerosos ejemplos nos muestran cómo, de forma recurrente, ha habido tensiones entre las comunidades y los usos o regímenes patrimoniales. El caso del patrimonio natural, quizás, sea el más evidente. A lo largo del planeta, encontramos numerosos ejemplos de una oposición abierta a la declaración de un área protegida ${ }^{13}$. La patrimonialización de la naturaleza ha supuesto la reordenación territorial de más del $16,64 \%$ de la superficie terrestre y del 7,74 \% del medio marino en el mundo, un aumento de más de 21 millones de $\mathrm{km}^{2}$, tan solo en la última década, según recoge el último Protected Planet Report 2020 (Bingham et ál. 2021). Se espera cumplir así con la Meta 11 Aichi adoptada en el Convenio sobre la Diversidad Biológica en $2010^{14}$. Este crecimiento drástico, iniciado en las décadas anteriores, es un fenómeno con importantes repercusiones sociopolíticas, jurídicas y económicas sobre las comunidades locales. El modelo patrimonial de la naturaleza se ha basado en una triple expropiación: del territorio, de las condiciones sociales de producción y de los conocimientos y memorias. Hasta el punto de que algunos autores consideran que, en algunos casos, ha provocado bien "refugiados de la conservación", bien "gentrificación de lo natural" (Dowie 2009; Phillips et ál. 2008; Santamarina Campos 2009) ${ }^{15}$. El propio informe Protected Planet reconocía la falta de datos sobre el manejo y la gobernanza, así como la necesidad de implantar una gobernanza equitativa. Además, establecía que solo a través de ella sería posible alcanzar una conservación eficaz (Bingham et ál. 2021). Admitía así que la protección no implica conservación -la denominación acuñada de "parques de papel" remite a ello- y que, sin el principio de equidad, no es posible garantizarla.

Los mismos procesos de conflicto los encontramos, en diferentes niveles y contextos, en el patrimonio material o inmaterial generados por la expropia-

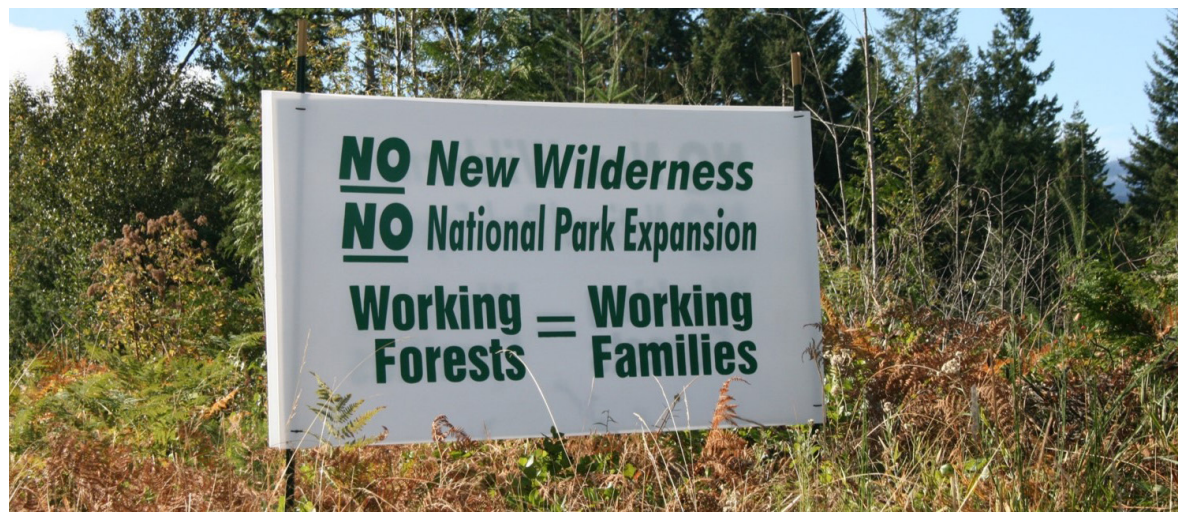




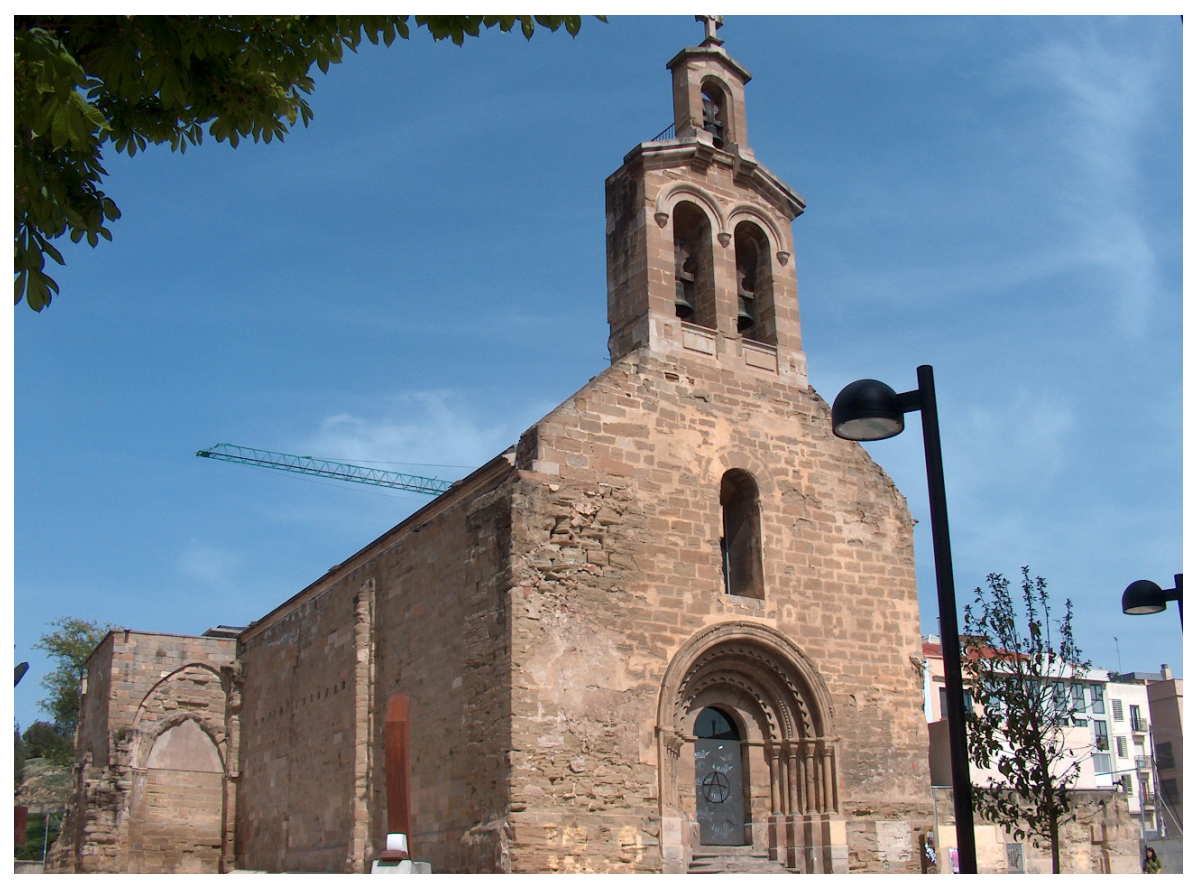

ción y reapropiación de los bienes por agentes externos, en muchos casos, avalados por expertos lo que legitima la propia sustracción. Múltiples ejemplos, en nuestro país, son repertorio de las tensiones generadas. Si más arriba hacíamos mención a las desavenencias generadas en una supuesta comunidad festiva por su patrimonio inmaterial, replicada en otras partes del mundo, lo mismo sucede con el material. Veámoslo a otro nivel, la Dama de Elche, los legajos de Catalunya o el Gernika de Picasso han sido objeto de disputa entre el Estado español y las administraciones autonómicas o locales (Santamarina Campos 2008). Del mismo modo, existen disputas entre las administraciones autonómicas. Pensemos, por ejemplo, en la portada románica de la iglesia de San Martín (Lleida), reclamada a Catalunya tanto por el Gobierno de Aragón, como por el pueblo oscense de El Tormillo. O entre locales, como sucede con la voluntad de recuperar la antigua iglesia románica de Santa María de Leorio, con parte en la vecina parroquia de La Pedrera (Asturias). E incluso entre otras instituciones, como el pleito por 111 obras entre las diócesis de Barbastro y Lleida. Este pequeño muestrario es significativo de la pugna por lo bienes patrimoniales. Contiendas, cada día más habituales, en una tesitura de inflación patrimonial, de versatilidad en la patrimonialización colectiva -con activaciones y demandas patrimoniales fuera de las esferas tradicionales de fabricación patrimonial, entrando nuevos objetos y sujetos- y de intensificación del consumo patrimonial (Santamarina y Vizcaíno 2021). Su rentabilidad ha acentuado los conflictos mostrando la competición por sus activos. En este particular paisaje, ¿puede el discurso patrimonial autorizado ceder espacio de poder para

Portada románica de la iglesia de San Martín (Lleida), reclamada a Catalunya tanto por el Gobierno de Aragón, como por el pueblo oscense de El Tormillo | foto João Carvalho 
16

"On the one hand, the taking over of bureaucratic paternalism by civil society has encouraged debate and activism as a counter-hegemonic approach toward radical socia transformation. On the other hand, the 'political decapitation' (Leal 2007) of participation will eventually create communities as enterprises claiming and managing collective intellectual property rights over traditional knowledge and complying with neoliberal models (Yúdice 2004, 6-7). Individual actors and communities may have good reasons to bolster their cultural identity by increasing its salability" (Adell et ál. 2015, 10).

\section{7}

"A los efectos de la presente Convención, se tendrá en cuenta únicamente el patrimonio cultural inmaterial que sea compatible con los instrumentos internacionales de derechos humanos existentes y con los imperativos de respeto mutuo entre comunidades, grupos e individuos y de desarrollo sostenible" (Disposiciones generales, Artículo 2) la participación? La participación supone tomar parte y recibir parte de algo. Participar implica acción y reconocimiento para entrar en los entresijos del dominio patrimonial. Y ello no es baladí, está en juego definir qué y quién es el portador, legítimo y titular, y quién y por qué debe ser su garante y gestor.

Dicho esto, la entrada (inocente) de la participación, suponía en principio, un vuelco normativo, con numerosos alcances jurídicos, económicos, políticos y sociales. La ambigüedad estaba servida efectuándose lecturas más éticas que políticas y sin implicaciones con impacto. De ahí, que la inherente ambivalencia del "nuevo paradigma participativo" haya sido ampliamente señalada y discutida (Adell et ál. 2015, 10) ${ }^{16}$. En nuestro país, el debate entre participación y patrimonio también ha sacado a luz los lindes, las contradicciones, los riesgos, así como las oportunidades (Cortés-Vázquez, JiménezEsquinas y Sánchez-Carretero 2017; Quintero Morón y Sánchez-Carretero 2017; Quintero-Morón 2020; Carrera Díaz 2019; Sánchez-Carretero et ál. 2019; Sánchez-Carretero y Roura-Expósito 2021; Quintero Morón y SánchezCarretero 2021). De estos trabajos se desprende, tal y como apuntábamos más arriba, cómo la participación, hasta ahora, ha sido mínima y utilizada como maquillaje de las políticas patrimoniales. En palabras de QuinteroMorón y Sánchez-Carretero "no ha producido una mayor presencia de las comunidades locales en los procesos de toma de decisión (...) el efecto de empoderamiento para las 'comunidades, grupos y en algunos casos individuos', que supuestamente traería consigo el giro participativo, dista mucho de haberse producido" $(2017,60)$. Los límites de la participación junto con el cambio en los acentos ontológicos (del tener al ser), identitarios (las comunidades locales portadoras), económicos (bienes y servicios envasados) y tecno-científicos (aumento de especialistas y burocratización) complejizan el panorama actual. La producción de usos del pasado es ahora más lucrativa que nunca, por ello se hacen urgentes medidas para garantizar una gobernanza sostenible. Y la sostenibilidad está recogida en la propia Convención del 2003, apareciendo en su abertura y en su cierre. Atendamos ahora a su centralidad, a su urgente necesidad y a su modulación en la Agenda 2030 instada por la Asamblea General de la Organización de Naciones Unidas (ONU).

\section{HACIA UN PATRIMONIO COLECTIVO SOSTENIBLE}

No deja de sorprender que, en el preámbulo de la Convención, se afirmara que el patrimonio cultural inmaterial es "garante del desarrollo sostenible". Desde nuestra consideración, darlo por hecho supone volver a traer a colación la imagen del buen salvaje. Más interesante resulta que, en el artículo 2 , tras la definición del patrimonio inmaterial, se exprese, entre otros requisitos $^{17}$, la obligatoriedad de su compatibilidad con el desarrollo sostenible. Su aparición respondía a la institucionalización internacional de su fórmula, desde el Informe Brutland (1987), como instrumento de catalización para 
los problemas medio ambientales. Dejando de lado la polémica del término y su forzada inclusión en la Convención, rescataremos aquí la sostenibilidad como un elemento fundamental para alcanzar la democratización y, por ende, la participación patrimonial. En lo que sigue, entenderemos la sostenibilidad como un paradigma posible y realizable articulado en los principios de responsabilidad, justicia e igualdad.

En 2015 la ONU presentaba la Agenda 2030 para el Desarrollo Sostenible. El documento desplegaba un plan de acción consensuado "a favor de las personas, el planeta y la prosperidad"18 a través de diecisiete Objetivos para el Desarrollo Sostenible (ODS) y con ciento sesenta y nueve metas socioeconómicas y ambientales. Las medidas y los objetivos permiten innumerables análisis y ser aplicados en todos los ámbitos de trabajo. Entre ellos podemos observar cómo el patrimonio colectivo puede convertirse en herramienta para alcanzar los ODS, más que ser de entrada compatible con los mismos. Su contribución, en la conservación o salvaguardia como contenedor de nuestro mejor legado para el futuro, pasa por responder a los principios básicos de la sostenibilidad para garantizar su protección.

La clasificación en material, inmaterial y natural puede ser útil a la hora de vincular los distintos patrimonios con los ODS. Por poner un ejemplo, el objetivo 15, "Proteger, restaurar y promover la utilización sostenible de los ecosistemas terrestres, gestionar de manera sostenible los bosques, combatir la desertificación y detener y revertir la degradación de la tierra, y frenar la pérdida de diversidad biológica" podemos ligarlo con la conservación del patrimonio natural. Aunque, esta aparente ventaja, puede traducirse en dificultad, al menos, en dos sentidos. Por un lado, los ODS pueden estar relacionados con los tres patrimonios: garantizar "una vida saludable y promover el bienestar" (ver objetivo 3) estaría unido al patrimonio natural, con las desiguales concepciones ecosistémicas ${ }^{19}$; al inmaterial, con diferentes cosmovisiones sobre el bienestar20; y al material, con las variadas arquitecturas y bienes coligados. Por otro lado, los ODS no se pueden conquistar si no se encaran los objetivos encadenados, de igual modo que la compartimentación patrimonial tampoco ayuda a esbozar políticas de (co)gestión con una visión integradora del territorio.

En las últimas décadas, la fábrica patrimonial ha respondido con creces a las exigencias del capital y de la economía creativa funcionando a la perfección el dueto patrimonio/turismo en el mercado global de los intangibles (Comaroff y Comaroff 2009; Boltanski y Chiapello 2006; Mármol y Santamarina 2019) ${ }^{21}$. En este contexto, la Unesco certifica el patrimonio y con ello garantiza la recepción de capitales (Meskell 2013, 2014). Ahora bien, su seno perpetúa las asimetrías ${ }^{22}$ calcando las desigualdades internacionales (Meskell et ál. 2015; Meskell y Brumann 2015). Todo ello sumado a la imposición de una única versión del patrimonio hegemónico y una excesiva burocratización,

\section{8}

Disponible en: https://www.un.org/sustainabledevelopment/es/2015/09/la-asamblea-general-adopta-la-agenda-2030-para-el-desarrollosostenible

19

Variedades ontológicas, por ejemplo, en la representación de lo humano y no humano.

20

Reparemos, como muestra, en el modelo del "buen vivir" (Sumak Kawsay).

21

El patrimonio al servicio del marcado es algo que públicamente no se reconoce (Hafstein 2009).

22

Tanto en su estructura política como en la toma de decisiones. 
23

Dejamos fuera las candidaturas pluriestatales e incluimos el Registro de Buenas Prácticas de Salvaguardia.

24

También debe tenerse en cuenta la sintonía entre los gobiernos estatal y autonómico; en el caso valenciano esto es manifiesto.

25

La mayoría de los bienes se concentran en espacios urbanos.

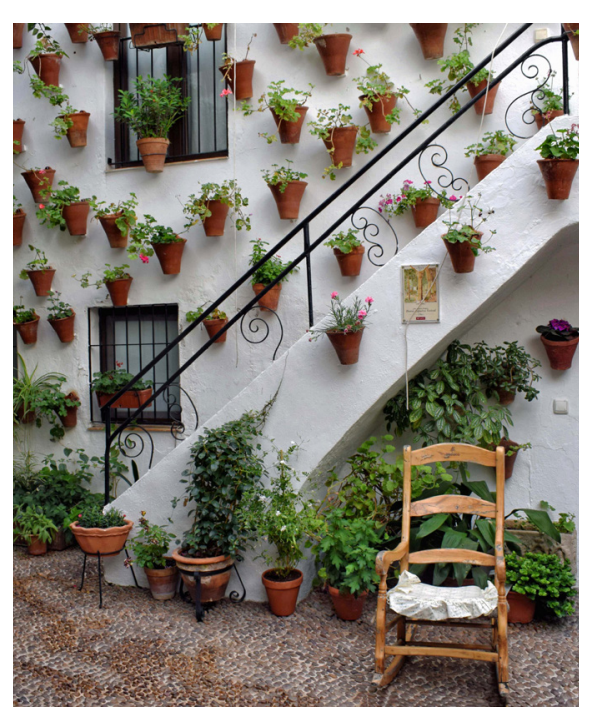

Las activaciones responden más a la oferta y demanda (turística) que a una salvaguardia de la extraordinaria diversidad. En la foto, Patios de Córdoba, declarados por la Unesco Patrimonio Cultural Inmaterial de la Humanidad | foto Jocelyn Erskine-Kellie lo que abre un abismo entre países (Martínez, Baraja y Molinero 2019). El resultado es obvio: países condecorados, países marginados. En realidad, en estos momentos, podemos afirmar que las listas de Patrimonio Mundial (1972) y de la Humanidad (2003) son obstáculos para poner el patrimonio colectivo al servicio de la sostenibilidad. En primer lugar, porque reproduce el sistema neocapitalista y neoliberal contribuyendo a la concentración de capitales. En segundo lugar, porque impide la pluralidad de sentidos, afectos y emociones del patrimonio colectivo. $Y$, en tercer lugar, porque reduce lo patrimonial a los dictados de los cuerpos técnicos y al acopio de informes y papeleo.

El esquema se repite, a otra escala, al descender a lo estatal y lo local. Veamos lo sucedido en España y en la Comunidad Valenciana, en el caso del patrimonio inmaterial. En la última década, la presentación de candidaturas y las declaraciones han ido en aumento. En la esfera estatal ${ }^{23}$, si atendemos, a los expedientes presentados para su incorporación en Lista de Patrimonio Cultural Inmaterial $(\mathrm{PCl})$ de la Humanidad, observaremos cómo se han enfrentado las comunidades autónomas (CC.AA.) entre ellas, en su afán por obtener el sello Unesco (Santamarina en prensa). Las CC.AA. más beneficiadas han sido las que tienen mayores recursos o un sector turístico muy consolidado, concentrándose en el arco mediterráneo. De los quince bienes incluidos en la Lista de $\mathrm{PCl}$ en el Estado español, cinco están en la Comunidad Valenciana, tres en Catalunya y tres Andalucía ${ }^{24}$. En lo local, los municipios valencianos, con más recursos, son los que presentan un mayor número de expedientes y, en conjunto, son las capitales de las provincias y de las comarcas las más beneficiadas (Santamarina 2017). Esto se traduce en una discriminación ${ }^{25}$, estatal y local, que aumenta las desigualdades territoriales. Además, en ambos casos, la mayoría de los bienes declarados pertenecen al ámbito de lo festivo, por ejemplo, en la Lista PCI, nos encontramos el Misterio de Elche, La Patum de Berga, los Castells, el Flamenco, el Canto de la Sibila, la fiesta de la Mare de Déu de Algemesí, las Fallas, los Patios de Córdoba, las Tamborradas o los Caballos del Vino. Esto supone relegar otros espacios patrimonializables y nos habla de la noción restringida del patrimonio inmaterial relacionada con la visión folclórica y, sobre todo, con el sector turístico por su capacidad imantadora. Las activaciones responden más a la oferta y demanda (turística) que a una salvaguardia de la extraordinaria diversidad española o valenciana, y revela la inexistencia de una política efectiva para la salvaguardia inmaterial. Hoy el mercado coloca el patrimonio colectivo como un gran activo económico (Bendix 2009; Timothy 2018). La pugna por tener y ser patrimonio establece una competición exógena, entre países, y endógena, entre el Estado y las CC.AA., entre las CC.AA. y las localidades y entre los distintos actores de las comunidades.

Después de lo visto hasta el momento, cabe plantearse ¿hay en lo patrimonial patrones de desarrollo? ¿son estos sostenibles? Con respecto a la pri- 

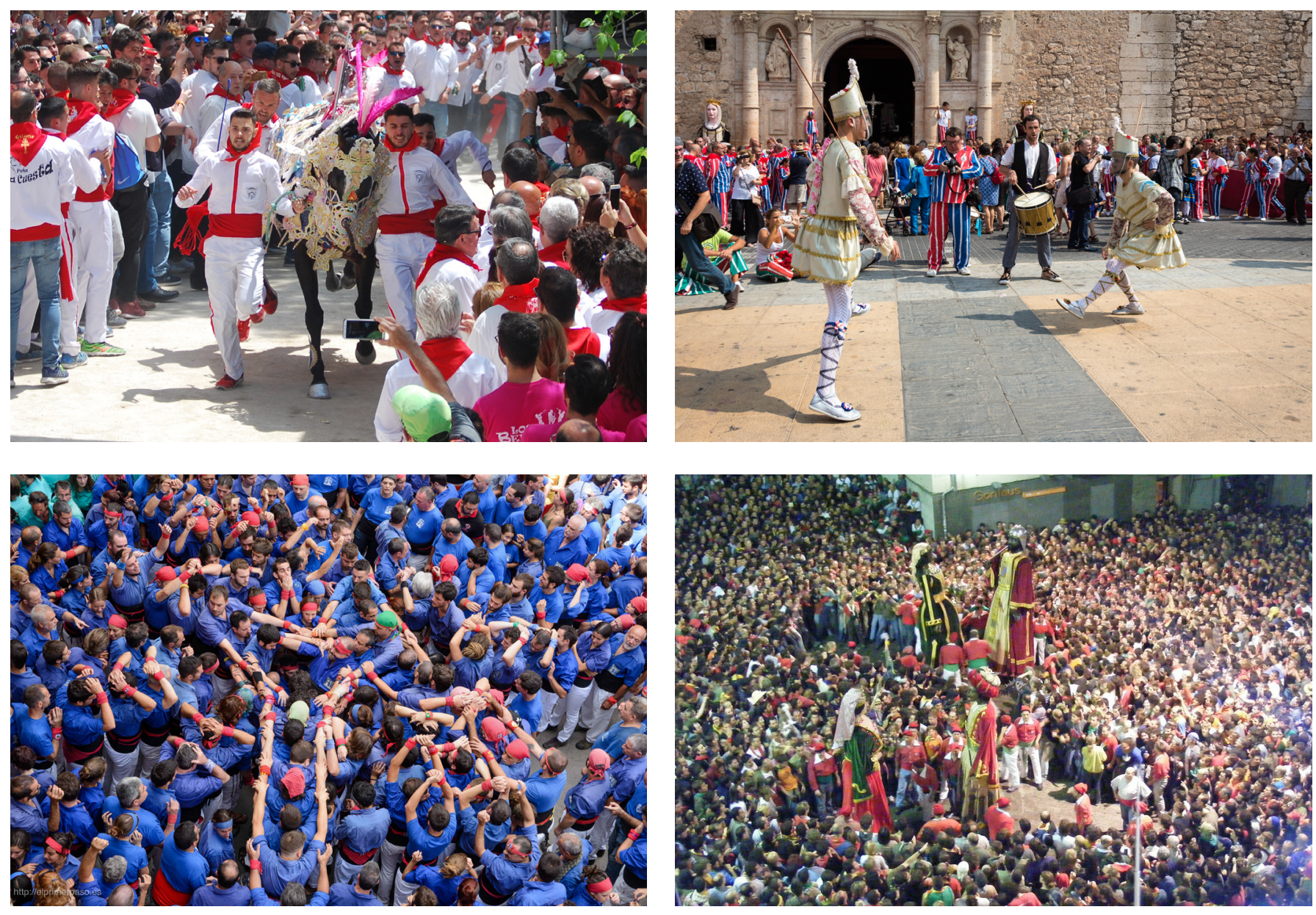

La mayoría de los bienes declarados pertenecen al ámbito de lo festivo, por ejemplo, en la Lista $\mathrm{PCl}($...) Esto supone relegar otros espacios

mera pregunta, podemos contestar afirmativamente. El problema radica en la forma de desarrollo seguido, sometido a los dictados del capitalismo sin capital (Haskel y Westlake 2017), lo que provoca una creciente mercantilización del patrimonio colectivo. La respuesta a la segunda se deriva de la primera, y es negativa; todavía no hay una visión del patrimonio sostenible y menos aún que integre los ODS. Y formulemos las últimas, ¿puede contribuir el patrimonio colectivo a la sostenibilidad? Desde nuestra visión, sí. patrimonializables y nos habla de la noción restringida del patrimonio inmaterial relacionada con la visión folclórica y, sobre todo, con el sector turístico por su capacidad imantadora. En las imágenes, Caballos del vino, fiesta de la Mare de Déu de Algemesí, los Castells y La Patum de Berga I fotos (de arriba a abajo y de izquierda a derecha) Conchi Arroyo, Rafa Esteve, El primer paso blog, Ràdio Berga La maquinaría patrimonial puede ponerse al servicio de la sostenibilidad. ¿Cómo? Su activación debe pasar por someterse y respetar los lugares y las personas a través de su protagonismo activo y de reconocer, asimismo, la enorme fragilidad del patrimonio colectivo. La mediación, en primera instancia, y participación social, en segunda, deben convertirse en instrumentos fundamentales en las activaciones y la cogestión. Solo así se puede lograr proteger y sostener a los lugares y personas, porque la protección en sí misma no asegura ni la conservación ni la salvaguardia. El principio del beneficio económico para unos pocos, pilar del sistema actual, y la ganancia 
patrimonial, debe mudarse hacia la máxima del beneficio social redistributivo y equitativo. $Y$ esto pasa: primero, por reconocer la titularidad y la propiedad de los bienes donde la responsabilidad y la justicia prime por encima de la expropiación; segundo, por estimular modelos de producción sostenibles y respetuosos donde los locales sean sus impulsores y protagonistas; $y$, tercero, por promover y contribuir a la igualdad entre todas y todos, al respeto a las distintas formas identitarias y a la dignidad de lo humano (y no humano). Todo ello está contemplado en los ODS y puede sintetizarse en garantizar la biodiversidad, entendida en sentido amplio, es decir, englobando a la diversidad cultural. Para alcanzar las metas y los ODS, el patrimonio colectivo debe redefinirse en todos los ámbitos (políticos, técnicos, económicos y sociales).

\section{(IN) CONCLUSIONES}

Hoy, la crisis socioecosistémica globalizada nos apremia a cambiar las lógicas imperantes en nuestro sistema político-económico. El patrimonio colectivo es una baza hacia la sostenibilidad, al promover la conservación y salvaguardia de la biodiversidad. Las comunidades deben participar activamente en la definición del lugar donde viven y de aquello que les representa de forma plural (la forma de ser, el modo de hacer y la manera de sentir) y deben ser agentes polifónicos en las decisiones sobre su patrimonio.

Para lograrlo, el primer paso es reconocer la titularidad del patrimonio, en sus distintos formatos, y la mediación dentro de las propias comunidades y con las administraciones. A partir de ahí, la participación debe entrar en escena y su éxito pasa por renovar, entre otros factores, a los cuerpos técnicos y disciplinarios. La participación comporta el empoderamiento y el reconocimiento de una pluralidad de sentidos, por tanto, las parcelas de poder deben reconfigurarse poniendo el acento en el territorio(s), la memoria(s), el conocimiento(s) y la identidad(es). El mayor peligro del giro participativo es el desgaste y frustración social ante promesas diluidas. Obviamente, la participación real supone una auténtica transformación en el gobierno de lo patrimonial, dado que implica una cesión de poder, un reconocimiento de derechos y propiedades y una cotutela en la gestión. Y, al mismo tiempo, conlleva desarticular, ontológica, epistemológica y metodológicamente, las codificaciones ejercidas desde el AHD (cultura/naturaleza; material/inmaterial).

La cimentación de nuevos patrimonios apoyados en la mediación y la participación, para alcanzar modelos de gobernanza sostenible, son fundamentales para frenar la degradación socioecológica. Alimentar la diferencia y la biodiversidad socioecosistémica es cardinal para dar alcance a la sostenibilidad y la mejor apuesta para la conservación y la salvaguardia patrimonial. Sin duda, el patrimonio colectivo es un campo privilegiado para la aplicación de la Agenda 2030, siendo un medio más para garantizar la sostenibilidad. 
El desplazamiento de la posesión, propiedad y titularidad patrimonial hacia la comunidad y su implicación en la gestión, desprendida de las normativas de la Unesco, es trascendental y debe materializarse. La definición de los sujetos (de quién es, para quién es) y de los objetos (el qué es, para qué es) de los procesos patrimoniales es el punto de partida hacia a la apertura. Parafraseando a Quintero-Morón, el giro participativo y los objetivos para el desarrollo sostenible son una oportunidad "para repolitizar la participación y orientarla a procesos de equidad y justicia social" $(2020,140)$. 


\section{BIBLIOGRAFÍA}

- Adell, N., Bendix, R., Bortolotto, Ch. y Tauschek, M. (2015) Between Imagined Communities and Communities of Practice: Participation, Territory and the Making of Heritage. Göetingen: Universitätsverlag Göttingen

- Aikawa, N. (2004) Visión histórica de la Preparación de la Convención Internacional de la UNESCO para la Salvaguardia del Patrimonio Cultural Inmaterial. Museum International, n. ${ }^{\circ} 221$, pp. $140-153$

- Albert Rodrigo, M. (2005) El patrimonio cultural y la sociedad civil. En: Hernández i Martí, G.M., Santamarina Campos, B., Moncusí Ferré, A. y Albert Rodrigo, M. (coord.) La memoria construida. Patrimonio cultural y modernidad. Valencia: Tirant Lo Blanch, pp. 193-223

- Alonso González, P. (2017) El antipatrimonio. Fetichismo y dominación en Maragatería. Madrid: CSIC

- Anderson, B. (1983) Imagined communities: reflections on the origins and spread of capitalism. Londres: Verso

- Ariño Villarroya, A. (2002) La expansión del patrimonio cultural. Revista de Occidente, n. ${ }^{\circ} 250$, pp. 129-150

- Ashworth, G.J. y Van der Aa, B.J. (2006) Strategy and policy for the world heritage convention: goals, practices and future solutions. En: Leask, A. y Fyall, A. (ed.) Managing world heritage sites. London: Elsevier, pp. 147-158

- Askew, M. (2010) The magic list of global status: UNESCO, World Heritage and the agendas of states. Heritage and Globalisation. En: Labadi, S. y Long, C. (ed.) Heritage and globalization. Londres: Routledge, pp. 19-44

- Beltrán, O. y Santamarina, B. (2016) Antropología de la conservación en España. Revista antropología social, vol. 25, n. ${ }^{\circ}$, pp. $85-109$

- Bauman, Z. (2001) Community: Seeking Safety in an Insecure World. Cambridge: Polity Press

- Bauman, Z. (2004) Identity. Cambridge: Polity Press

- Bauman, Z. (2005) Modernidad y ambivalencia. Barcelona: Anthropos

- Bauman, Z. (2017) Retrotopia. Cambridge: Polity Press

- Bendix, R., Eggert, A. y Peselmann, A. (ed.) (2013) Heritage Regimes and the State. Göttingen: Universitätsverlag Göttingen

- Bendix, R. (2009) Heritage between Economy and Politics: An Assessment from the Perspective of Cultural Anthropology. En: Smith, L. y Akagawa, N. (ed.) Intangible Heritage. Londres: Routledge, pp. 253-269

- Bingham, H.C., Lewis, E., Tayleur, J., Cunningham, C., Kingston, N., Burgess, N., Ash, N., Sandwith, T. y MacKinnon, K. (ed) (2021) Protected Planet Report 2020. Cambridge: UNEP-WCMC: Disponible en: https://livereport. protectedplanet.net/ [Consulta: 29/07/2021]

- Boltanski, L y Chiapello, E. (2002) El nuevo espíritu del capitalismo. Madrid: Akal

- Bortolotto, Ch. (2011) (ed.) Le patrimoine culturel immatériel: enjeux d'une nouvelle catégorie. París: Maison des Sciences de l'Homme

- Bourdieu, P. (1998) La distinción. Criterio y bases sociales del gusto. Madrid: Taurus

- Bourdieu, P. (1991) El sentido práctico. Madrid: Taurus

- Bourdieu, P. (1997) Razones prácticas. Sobre la teoría de la acción. Barcelona: Anagrama

- Boym, S. (2016) El futuro de la nostalgia. Madrid: Antonio Machado Libros

- Carrera Díaz, G. (2019) Participación social, patrimonialización "expandida" y nuevos sujetos patrimoniales. En: Sánchez-Carretero, C., MuñozAlbadalejo, J., Ruiz-Blanch, A. y Roura-Expósito, J. (ed.) El imperativo de la participación en la gestión patrimonial. Madrid: CSIC, pp. 217-235

- Casado de Otaola, S. (2010) Naturaleza Patria. Ciencia y sentimiento de la naturaleza en la España del regeneracionismo. Madrid: Fundación Jorge Juan-Marcial Pons

- Cesari, C. de (2013) Thinking Through Heritage Regimes. En: Bendix, R., Eggert, A. y Peselmann, A. (ed.) Heritage Regimes and the State. Göttingen: Universitatsverlag Gottingen, pp. 399-413

- Comaroff, J. y Comaroff, J. (1991) Of Revelation and Revolution. Chicago: University of Chicago Press

- Comaroff, J. y Comaroff, J. (2009) Etnicidad S.A. Madrid: Katz

- Coombe, R.J. y Weiss, L. (2015) Neoliberalism, Heritage Regimes, and Cultural Rights. En: Meskell, L. (ed.) Global Heritage: A Reader. Oxford: Wiley-Blackwell, pp. 43-69

- Cortés-Vázquez, J.A., Jiménez-Esquinas, G. y SánchezCarretero, C. (2017) Heritage and participatory governance: An analysis of political strategies and social fractures in Spain. Anthropology Today, vol. 33, n. ${ }^{\circ}$ 1, pp. 15-18

- Choay, F. (1996) L'allégorie du patrimoine. París: Seuil

- Daniels, S. (1993) Fields of Vision: Landscape Imaginary and National Identity in England and the United States. Princeton: Princeton University Press

- Davallon, J. (2014) El juego de la patrimonialización. En: Roigé, X., Frigolé, J. y Mármol, C. del (coord.) Construyendo el patrimonio cultural y natural. Parques, museos y patrimonio rural. Valencia: Germania, pp. 47-76 
- Dowie, M. (2009) Conservation refugees: the hundred year conflict between global conservation and native peoples. Cambridge: MIT Press

- Foucault, M. (1980) Power/knowledge: Selected interviews and other writings, 1972-1977. Nueva York: Pantheon Books

- Frigolé, J. (2014) Retóricas de la autenticidad en el capitalismo avanzado. Endoxa , n. ${ }^{\circ} 33$, pp. 37-60. Disponible en: https://doi.org/10.5944/endoxa.33.2014.13564 [Consulta: 28/07/2021]

- García Canclini, N. (1999) Los usos sociales del patrimonio cultural. En: Aguilar Criado, E. (coord.) Patrimonio Etnológico. Nuevas perspectivas de estudio. Granada: Junta de Andalucía, Instituto Andaluz del Patrimonio Histórico, pp.16-33

- Geismar, H. (2015) Anthropology and heritage regimes. Annual Review of Anthropology, vol. 44, pp. 7185. Disponible en: https://www.annualreviews.org/doi/abs/ 10.1146/annurev-anthro-102214-014217 [Consulta: 28/07/ 2021]

- Gómez Ferri, J. (2004) Del patrimonio a la identidad. La sociedad civil como activadora patrimonial en la ciudad de Valencia. Gazeta de Antropología, vol. 20, n. ${ }^{\circ}$ 9. Disponible en: http://www.ugr.es/ pwlac/G20_09Javier_Gomez_Ferri. html [Consulta: 28/07/2021]

- González-Varas, I. (1999) Conservación de bienes culturales: teoría, principios y normas. Madrid: Cátedra

- González-Varas, I. (2015) Patrimonio cultural: conceptos, debates y problemas. Madrid: Cátedra

- Hafstein, V. (2009) Intangible Heritage as a List. From Masterpieces to Representation. En: Smith, L. y Akagawa, N. (ed.) Intangible Heritage. New York: Routledge, pp. 93-111

- Hall, S. (2003) Who Needs 'Identity'? En: Hall S. y Du Gay, P. (ed.) Questions of Cultural Identity. London: Sage, pp. 1-17

- Hall, S. (2010) Identidad cultural y diáspora. En: Restrepo, E., Walsh, C. y Vich, V. de. Sin garantías: Trayectorias y problemáticas en estudios culturales. Popoyán: Envión editors, pp. 349-361

- Hall, S. (2003) Who Needs 'Identity'? En: Hall S. y Du Gay, P. (ed.) Questions of Cultural Identity. London: Sage, pp. $1-17$

- Haskel, J. y Westlake, S. (2017) Capitalism without Capital: The Rise of the Intangible Economy. Nueva York: Princeton University Press

- Heinich, N. (2010) La fabrique du patrimoine. De la cathédrale à la petite cuillère. París: Maison des Sciences de l'Homme
- Hernández i Martí, G.M., Santamarina Campos, B., Moncusí Ferré, A. y Albert Rodrigo, M. (2005) La memoria construida. Patrimonio cultural y modernidad. Valencia: Tirant Lo Blanch

- Herzfeld, M. (2004) The Body Impolitic: Artisans and Artifice in the Global Hierarchy of Value. Chicago: University of Chicago Press

- Hobsbawm, E. y Ranger, T. (2005) La invención de la tradición. Barcelona: Crítica

- Kurin, R. (2004) La salvaguardia del patrimonio cultural inmaterial en la Convención de la UNESCO de 2003: una valoración crítica. Museum International, n. ${ }^{0} 221$, pp. 68-81

- Kuutma, K. (2013) Between arbitration and engineering: Concepts and contingencies in the shaping of heritage regimes. En: Bendix, R., Eggert, A. y Peselmann, A. (ed.) Heritage Regimes and the State. Göttingen: Universitätsverlag Göttingen, pp. 21-36

- Labadi, S. (2007) Representations of the nation and cultural diversity in discourses on World Heritage. Journal of Social Archaeology, vol. 7, n. ${ }^{\circ}$ 2, pp. 147-170

- Lowenthal, D. (1998) El pasado es un país extraño. Barcelona: Akal

- Mármol, C. del, Morell, M. y Chalcraft, J. (ed.) (2015) The making of heritage: Seduction and disenchantment. London: Routledge

- Mármol, C. del, Roigé, X. y Estrada, F. (2011) Safeguarding Intangible Cultural Heritage? A critical perspective on the inventory of Intangible Cultural Heritage in Catalonia. En: Lira, Sérgio, Amoêda, R., Pinheiro, C. (coord.) Sharing Cultures 2011. Portugal: Green Lines Institute for Sustainable Development, pp. 481-490

- Mármol, C. del (2017) Pasados locales, políticas globales: procesos de patrimonialización en un valle del Pirineo catalán. Valencia: Neopatria

- Mármol, C. del y Estrada F. (2018) Naturalizing culture in the Pyrenees: Heritage processes in rural contexts. En: Arregui, A., Mackenthun, G. y Wodianka, S. (ed.) Decolonizing Heritage: Natures, Cultures and the Asymmetries of Memory. Münster: Waxmann Verlag, pp. 219-236

- Mármol, C. (Del), Frigolé, J. y Narotzky, S. (ed.) (2010) Los lindes del patrimonio. Consumo y valores del pasado. Barcelona: Icaria

- Mármol, C. del, Siniscalchi, V. y Estrada, F. (2016) Reflecting on heritage and power: dynamics, strategies and appropriations in the Catalan Pyrenees and the French Alps. International Journal of Heritage Studies, vol. 22, n. ${ }^{\circ}$ 5, pp. 341-354

- Mármol, C. del y Santamarina, B. (2019) Seeking 
Authenticity: Heritage and Value within the Intangible Economy. Journal of Mediterranean Studies, vol. 28, n. ${ }^{\circ}$, pp. 117-132

- Martínez, M., Baraja, E. y Molinero, F. (2019) Criterios de la UNESCO para la Declaración de Regiones Vitícolas como Paisaje Cultural. AGE, vol. 80, n. ${ }^{\circ} 2614$, pp. 1-33

- Meskell, L. y Brumann, C. (2015) UNESCO and new world orders. En: Meskell, L. (ed.) Global Heritage. Malden: John Wiley \& Sons, pp. 22-42

- Meskell, L., Liuzza, C., Bertacchini, E. y Saccone, D. (2015). Multilateralism and UNESCO World Heritage: Decision-Making, States Parties and Political Processes. International Journal of Heritage Studies, vol. 21, n. $^{0} 5$, pp. 423-40

- Meskell, L. (2013) UNESCO's World Heritage Convention at 40: Challenging the economic and political order of international heritage conservation. Current Anthropology, vol. 54, n. ${ }^{\circ} 4$, pp. 483-494

- Meskell, L. (2014) States of conservation: Protection, politics, and pacting within UNESCO's world heritage committee. Anthropological Quarterly, vol. 87, n. ${ }^{0} 1$, pp. 217-243

- Montenegro Riveros, M. (2010) La patrimonialización como protección contra la mercantilización: paradojas de las sanciones culturales de lo igual y lo diferente. Revista Colombiana de Antropología, vol. 46, n. ${ }^{\circ}$ 1, pp. 115-131

- Noyes, D. (2011) La fête ou le fétiche, le geste ou la gestion. Du patrimoine culturel immatériel comme effet pervers de la démocratisation. En: Bortolotto, Ch. (ed.) Le patrimoine culturel immatériel: enjeux d'une nouvelle catégorie. Paris: Éditions de la Maison des sciences de l'homme, 2011, pp. 125-148

- ONU [Organización de las Naciones Unidas] (2015) Transformar nuestro mundo: la Agenda 2030 para el Desarrollo Sostenible. Disponible en: https://unctad. org/meetings/es/SessionalDocuments/ares70d1_es.pdf [Consulta: 29/07/2021]

- Pavone, V. (2008) From the Labyrinth of the World to the Paradise of the Heart: Science and Humanism in UNESCO's Approach to Globalization. New York: Lexington

- Phillips, M., Page, S., Saratsi, E., Tansey, K., y Moore K. (2008) Diversity, scale and green landscapes in the gentrification process: Traversing ecological and social science perspectives. Applied geography, vol. 28, n. $^{\circ} 1$, pp. 54-76

- Poulot, D. (2006) Une histoire du patrimoine en Occident, XVIII-XIX siècle. Du monuments auX valeurs. París: Presses Universitaires de France

- Prats, L. (1997) Antropología y patrimonio. Barcelona: Ariel
- Quintero Morón, V. y Sánchez-Carretero, C. (2021) La salvaguarda del $\mathrm{PCl}$ : trenzando acompañamiento etnográfico y procesos participativos. En: Carrera, G. (ed.) La salvaguarda del patrimonio cultural inmaterial como acuerdo social. Sevilla: Instituto Andaluz del Patrimonio Histórico (en prensa)

- Quintero-Morón, V. (2009) Los sentidos del patrimonio. Alianzas y conflictos en la construcción del patrimonio etnológico andaluz. Sevilla: Fundación Blas Infante

- Quintero-Morón, V. (2020) La participación en patrimonio y sus protagonistas. Límites, contradicciones y oportunidades. Revista $\mathrm{PH}, \mathrm{n}^{\circ}{ }^{\circ}$ 101. Disponible en: https://www.iaph.es/revistaph/index.php/revistaph/article/ view/4687 [Consulta: 29/07/2021]

- Quintero-Morón, V. y Sánchez-Carretero, C. (2017) Los verbos de la participación social y sus conjugaciones: contradicciones de un patrimonio democratizador. Revista Andaluza de Antropología, vol. 12, pp. 48-69

- Roigé, X. y Frigolé, J. (ed.) (2010) Constructing cultural and natural heritage. Parks, Museums and Rural Heritage. Girona: Institut Català de Recerca en Patrimoni Cultural

- Sánchez-Carretero, C. (2017) Hacia una antropología de conflicto aplicada al patrimonio. En: Santamarina Campos, B. (coord.) Geopolíticas patrimoniales. De culturas, naturalezas e inmaterialidades. Una mirada etnográfica. Valencia: Neopatria, pp. 215-230

- Sánchez-Carretero, C. y Roura-Expósito, J. (2021) Participación: usos, límites y riesgos en los proyectos patrimoniales. En: Arrieta Urtizberea, I. y Díaz Balerdi, I. (ed.) Patrimonio y museos locales: temas clave para su gestión. Tenerife: PASOS, pp. 339-357

- Sánchez-Carretero, C., Muñoz, J., Ruiz, A. y Roura, J. (ed.) (2019) El imperativo de la participación en la gestión patrimonial. Madrid: CSIC

- Santamarina Campos, B. (2008) Moros y cristianos. De la batalla festiva a la discursiva. Gazeta de Antropología, 2008, vol. 24, n. ${ }^{\circ}$ 1. Disponible en: https://www.ugr. es/ pwlac/G24 16Beatriz Santamarina_Campos.html [Consulta: 29/07/2021]

- Santamarina Campos, B. (2009) De parques y naturalezas. Enunciados, cimientos y dispositivos. Disparidades. Revista de Antropología, vol. 64, n. ${ }^{\circ} 1$, pp. 297-324. Disponible en: https://doi.org/10.3989/ rdtp.2009.78 [Consulta: 29/07/2021]

- Santamarina Campos, B. (2013) Los mapas geopolíticos de la Unesco: entre la distinción y la diferencia están las asimetrías. El éxito (exótico) del patrimonio inmaterial. Revista de Antropología Social, vol. 22, pp. 263-286. Disponible en: https://doi.org/10.5209/rev_RASO.2013. v22.43191 [Consulta: 28/07/2021] 
- Santamarina, B. (2021) The Global Competition of the Intangible. UNESCO as a Producer of Heritage Brands. Heritage \& Society (en prensa)

- Santamarina, B. (2017) El patrimonio inmaterial en el país valenciano: una explosión muy tangible. Revista Andaluza de Antropología, n. ${ }^{\circ} 12$, pp. 117-143. Disponible en: http://dx.doi.org/10.12795/RAA.2017.12.06 [Consulta: 29/07/2021]

- Santamarina Campos, B. y Mármol, C. del (2017) Ciudades creativas y pueblos con encanto: los nuevos procesos patrimoniales del siglo XXI. Revista de Dialectología y Tradiciones Populares, vol. 72 , n. ${ }^{\circ}$ 2, pp. 359-377. Disponible en: http://dra.revistas.csic.es/index. php/dra/article/view/547 [Consulta: 28/07/2021]

- Santamarina, B. y Mármol, C. del (2020) Para algo que era nuestro... Ahora es de toda la humanidad: El patrimonio mundial como expresión de conflictos. Chungara. Revista de Antropología Chilena, vol. 52, n. 1, pp. 161-173

- Santamarina, B., y Mompó, E. (2021) The Political Opportunity of Heritage: Appropriations, Memories, and Identities in Cabanyal. Anthropological Quarterly, vol. 94, n. ${ }^{\circ} 1$, pp. 34-64

- Santamarina, B., y Vizcaíno, T. (2021) Consuming the past into the present: The case of the Iberians (Valencia, Spain). International Journal of Cultural Property, pp. 1-16. Disponible en: https://doi.org/10.1017/S0940739120000302 [Consulta: 29/07/2021]

- Smith, L. (2006) Uses of heritage. New York: Routledge

- Tauschek, M. (2013) The bureaucratic texture of national patrimonial policies. En: Bendix, R., Eggert, A. y Peselmann, A. (ed.) Heritage Regimes and the State. Göttingen: Universitätsverlag Göttingen, pp. 195-212

- Timothy, D.J. (2018) Making sense of heritage tourism: Research trends in a maturing field of study. Tourism Management Perspectives, n. ${ }^{\circ} 25$, pp. 177-180

- Tunbridge, J. y Ashworth G. (1996) Dissonant Heritage: The Management of the Past as a Resource in Conflict. New York: John Wiley \& Sons

- UNESCO [Organización de las Naciones Unidas para la Educación, la Ciencia y la Cultura] (2003) Convención para la Salvaguardia del Patrimonio Cultural Inmaterial. París, 17 de octubre de 2003. Disponible en: http://portal.unesco.org/ es/ev.php-URL_ID=17716\&URL_DO=DO_TOPIC\&URL_ SECTION=201.httml [Consulta: 29/07/2021]

- Villasenor Alonso, I. y Zolla Marquez, E. (2012) Del patrimonio cultural inmaterial o la patrimonialización de la cultura, Cultura y representaciones sociales. Revista del Instituto de Investigaciones Sociales, vol. 6, n. ${ }^{\circ} 12$, pp. $75-$ 101
- Waterton, E. y Smith, L. (2010) The recognition and misrecognition of community heritage. International Journal of Heritage Studies, vol. 16, n. ${ }^{\circ}$ 1-2, pp. 4-15

- Winter, T. (2014) Beyond Eurocentrism? Heritage conservation and the politics of difference. International Journal of Heritage Studies, vol. 20, n. ${ }^{\circ} 2$, pp. 123-137 